\title{
CERVICO-OCULAR REFLEX UPREGULATION IN DIZZY PATIENTS WITH ASYMMETRIC NECK PATHOLOGY
}

\author{
EWA ZAMYSŁOWSKA-SZMYTKE ${ }^{1}$, TOMASZ ADAMCZEWSKI², JACEK ZIĄBER ${ }^{3}$, JOANNA MAJAK ${ }^{4}$, \\ JOLANTA KUJAWA ${ }^{2}$, and MARIOLA ŚLIWIŃSKA-KOWALSKA ${ }^{5}$
}

${ }^{1}$ Nofer Institute of Occupational Medicine, Łódź, Poland

Audiology and Phoniatrics Clinic, Balance Disorders Unit

${ }^{2}$ Medical University of Lodz, Lódź, Poland

Clinic of Medical Rehabilitation

${ }^{3}$ Holy Family Medical Hospital, Łódź, Poland

${ }^{4}$ Medical center "Medicover", Łódź, Poland

${ }^{5}$ Nofer Institute of Occupational Medicine, Łódź, Poland

Audiology and Phoniatrics Clinic

\begin{abstract}
Objectives: The aim of this study was to investigate whether the restriction in neck rotation and increased neck muscle tension could be causally related to vertigo and dizziness. Material and Methods: Seventy-one patients reporting vertigo and/or imbalance were divided into 2 groups: 45 subjects with unilateral restriction $(\mathrm{R}+)$ and 26 without restriction $(\mathrm{R}-)$ of cervical rotation and muscle tension in the clinical flexion-rotation test. The normal caloric test was the inclusion criterion. The control group comprised 36 healthy volunteers with no history of vertigo. The vestibulo-ocular reflex (VOR) and the cervico-occular reflex (COR) were measured through the videonystagmography (VNG) sinusoidal pendular kinetic test in the conditions of not inactivated head and immobilized head, respectively. The VNG-head torsion test (VNG-HTT) nystagmus was recorded. Results: Among the reported complaints, neck stiffness, headaches and blurred vision were more frequent in the $\mathrm{R}+$ group than in both the $\mathrm{R}-$ group and the control group. VNG revealed an increased COR gain and the presence of VNG-HTT nystagmus in the R+ group only. Similarly, only in the R+ group a positive relationship between COR and VOR was observed. Conclusions: Patients with asymmetric restriction in neck rotation and increased neck muscle tension reveal the tendency to have an increased response of the vestibular system, along with co-existing COR upregulation. Further research is needed to investigate the relationships between the activation of cervical mechanoreceptors and dizziness pathomechanisms. Int J Occup Med Environ Health. 2019;32(5):723-33
\end{abstract}

Key words:

muscle tension, proprioception, dizziness, afferents, cervical vertigo, COR upregulation

Funding: this study was supported by the National Centre for Research and Development (project No. Strategmed 2/266299/19NCBR/2016, part of the "Prevention and treatment of civilization diseases" program, entitled "Innovative system for evaluation and rehabilitation of human imbalance," project manager: Prof. Mariola Śliwinska-Kowalska).

Received: January 13, 2019. Accepted: August 26, 2019.

Corresponding author: Ewa Zamysłowska-Szmytke, Nofer Institute of Occupational Medicine, Audiology and Phoniatrics Clinic, Balance Disorders Unit, św. Teresy 8 , 91-348 Łódź, Poland (e-mail: zamysewa@imp.lodz.pl). 


\section{INTRODUCTION}

The cervical origin of headaches, dizziness or vertigo has been observed by specialists in combination with significant controversy due to the lack of evidence for a link between cervical abnormalities, symptoms and objective tests. In clinical practice, the cervical origin of vertigo and dizziness is a common, even if not fully proven, explanation offered to patients when no other reasons for their dizziness can be established. In consequence, symptoms of the functional origin may seriously handicap occupational practice and everyday living. Thus, there is a need for more clinical research, which could provide evidence to understand the problem of cervical dizziness and help to develop a treatment program for the affected subjects. The clinical syndrome of vertigo or dizziness that develops due to neck disorders has been named cervical dizziness. Cervical dizziness may arise when pathological or inappropriate cervico-postural and cervico-ocular reflexes interact with vestibular and visual cues. According to Brandt and Bronstein [1], symptoms of cervical dizziness would be "a sensation of lightheadedness or floating unsteadiness and slight ataxia of stance and gait, perhaps more on head turns," and their suspected mechanism is proprioceptive. It has been suggested by Hulse [2] that one-third of all cases of cervical dizziness are due to trauma, such as whiplash, one-third have an insidious onset following spinal degeneration, and one-third exhibit other causes. Hain [3] has described 3 main categories of cervical dizziness, depending of its origin: vascular, whiplash and cervical disorders other than whiplash. Hypothetically, patients with a whiplash associated disorder develop vertigo and imbalance due to disturbed proprioception in the facet joints of the cervical spine and deep muscles of the neck [4]. Cervical spondylosis is believed to be one of the causes of cervical dizziness although the literature contains data both for [5] and against this theory [6]. In the study by Colledge et al. [7] investigating the causes of dizziness in the elderly, the authors attributed dizziness to cervical spondylosis in $65 \%$ of cases. Vertigo or dizziness, cervical pain and a diminished range of cervical motion were reported by post-traumatic patients diagnosed with atlanto-axial subluxation (AAS), when atlanto-axial asymmetry was found in open-mouth anteroposterior (AP) radiographs. In addition, some degree of asymmetry was noticed in the CT study on a large Chinese population of subjects with no history of trauma or other spine diseases [8]. In several more or less serious diseases and clinical conditions listed above, dizziness may be attributed to a cervical pathology on the basis of possible pathophysiologic mechanisms.

Stimulation of the cervical afferent pathways has been recognized as one of the possible pathomechanisms of cervical dizziness. Unilateral stimulation of the neck with vibration stimuli generates a proprioceptive signal related to the head-to-trunk position, which can induce illusions of head tilt, head rotation and visual motion [9]. Weak, low-velocity nystagmus may be elicited in normal subjects by trunk rotation with the head immobilized and kept in the dark (thereby avoiding vestibular and visual stimulation). In such cases, cervico-occular reflex (COR) induces eye movements in response to proprioceptive signals from the neck. Animal studies suggest that cervical proprioceptive afferents send collaterals directly to the ipsilateral medial and inferior vestibular nuclei and, by disynaptic contralateral pathways, to the medial, inferior and lateral vestibular nuclei [10]. Then, COR includes central vestibulo-ocular reflex (VOR) pathways and is obscured by the other eye stabilization reflexes (vestibulo-ocular and optokinetic) [11]. The gain of COR varies, depending on the laboratory, from non-measurable [12-13] to $<0.25$ at $0.1 \mathrm{~Hz}$ rotation [14], or even 0.65 for low velocities [15]. The COR can partially compensate for a complete loss of the VOR function which was observed in studies on monkeys [16] and humans [17]. The COR gain increases with age (particularly $>60$ ), and there is a significant negative correlation between the gains of VOR and COR in older populations [15]. An increase in the COR gain with 
reduced neck mobility and the lack of synergy between VOR and COR were observed in patients with whiplashassociated disorders [18]. In that group of patients, a reduced cervical range of motion and a decreased relaxation ability of the cervical trapezoid muscles were observed. Montfoort et al. [18] have hypothesized that an increased COR may be caused by a reduced neck mobility while cerebellar disturbance may underlie the absence of adaptation of both COR and VOR.

Cervical dizziness is a clinical syndrome which probably incorporates multi-field cervical abnormalities. In theory, altered proprioception caused by damaged muscles, tendons and the fibrous capsules in joints may cause postural imbalance, visual target movement and vertigo. In practice, there is no clinical test to differentiate whether cervical dizziness develops, or does not develop, due to neck pathology [3]. Moreover, for the majority of neck symptoms, there is an absence of an identifiable underlying disease or an abnormal anatomical structure. The terms "mechanical neck disorder" and "non-specific neck pain" have been coined; those conditions are characterized by neck pain accompanied by headache, dizziness and a limited range of motion, which are unrelated to any systemic problems of the cervical spine or soft tissues. It has been proposed that these problems may result from lifestyle factors, habitual posture and external neck muscle imbalance $[19,20]$.

Since the pathogenesis of cervical dizziness is poorly recognized, and its link to the increased COR has not been proven, the aim of this study was to investigate whether the asymmetric restriction in neck rotation and increased neck muscle tension may activate the cervical afferent response, which in turn could be linked to dizziness.

\section{Description of study groups}

The study group prospectively included patients referred to the Audiology Clinic or the Neurology Department due to vertigo or dizziness. The patients' evaluation started with a careful neurological examination including cranial nerves and cerebellar function assessment. In the case of any doubt or deficit, the MRI was performed, which should be normal in order for the patient to be involved in the study. An ENT specialist performed an ear-nose-throat examination. Detailed questions were asked about hearing difficulties, ear fullness and tinnitus. Audiometric tests, such as pure tone audiometry, immittance audiometry and other relevant tests recommended by specialists, were performed to rule out middle and/ or inner ear pathologies. Those patients who presented hearing loss above their respective age-related values were excluded from the study. Finally, information was gathered about the potentially co-existing diseases, i.e., age-related cervical spondylosis, arrhythmia, hypertension, orthostatic hypotension, thyroid disease, diabetes, anemia, drug intake or psychiatric problems. Cardiac function and blood pressure (BP) were also assessed. Patients with serious and unstable internal problems were not included in the study. A very detailed headache interview was performed, intended to reveal subjects who met the criteria of primary headache (migraine, tension headache) specified in the International Classification of Headache Disorders, 3rd edition (ICHD-3). All the patients underwent videonystagmography (VNG) assessments: saccades, smooth pursuit, optokinetic, gaze nystagmus and bithermal Fitzgerald-Hallpike caloric tests. The most relevant neuro-otological criteria of exclusion from the study were as follows: vestibular imbalance in VNG (canal paresis > 19\%), benign paroxysmal positional vertigo (BPPV) signs in the Dix-Hallpike test, BPPV episodes during the previous year, Ménière's disease, serious head and neck traumas which involved the loss of consciousness and long-lasting hospitalization, migraine history and symptoms of cervical instability in the specialist physiotherapy examination (the Sharp-Purser and Aspinall tests for transverse ligament of atlas and alar ligament stress tests). 
Finally, 71 subjects (including 15 males) with dizziness of an unknown origin (other than the impairment of vestibular function) were involved in the study.

Two study groups were created based on 2 independent examinations: the flexion-rotation test (FRT) performed by a neurologist, and the atlanto-occipital and atlanto-axial mobility testing performed by a physiotherapy specialist. During FRT, the cervical spine was fully flexed and passively rotated to the right or left while noting the range of motion and pain. A one-side limited range of motion of $>10^{\circ}$ measured with goniometry, and the painful restriction in the joint play at the level of $\mathrm{C} 0-\mathrm{C} 2$, made the test positive in a yes-no manner. The physiotherapy examination was performed according to the Kaltenborn-Evjenth Orthopedic Manual Physical Therapy system in which muscle tension was evaluated by palpation of the trapezius, elevator scapulae, sternocleidomastoideus and suboccipital muscles. The consistent results of these 2 tests formed the basis for dividing the patients into 2 groups:

1) $45 R+$ patients with a one-side diminished range of cervical motion (age $(\mathrm{M} \pm \mathrm{SD}) 33.4 \pm 8.5$ years),

2) $26 \mathrm{R}$ - patients with no limits or restrictions in cervical rotation (age $(\mathrm{M} \pm \mathrm{SD}) 46.1 \pm 14.8$ years).

Finally, the open mouth AP X-ray examination was performed in all the study patients to evaluate the functional findings. The area of interest included cases where the odontoid peg was subtly rotated to the left or right with no anterior displacement of the atlas, and/or the lateral mass $\mathrm{C} 1$ was rotated and asymmetric. The radiographic assessment was blinded as for the clinical status of the patient. As a result of testing, $81 \%$ of the $\mathrm{R}+$ group revealed asymmetry in the open mouth AP X-ray examination while no such abnormality was found in the R-group.

Additionally, VNG tests were compared to the control group (C), which included 36 volunteers (mean age: 30.9 years, SD 6.1) with no history of vertigo, dizziness or headaches. The exclusion criteria were the same as listed above for the study groups. The FRT and physiotherapy examination did not reveal any diminished range of cervical motion in this group. There were no statistically significant age differences between the $\mathrm{R}+$ and $\mathrm{C}$ groups, while the subjects included in the $\mathrm{R}$ - group were generally older than those in the $\mathrm{R}+$ and $\mathrm{C}$ groups.

Informed consent was obtained from all the participants in this research.

\section{MATERIAL AND METHODS}

\section{Symptoms}

The patients were inquired in detail about such symptoms as vertigo, dizziness, imbalance, headaches and neck pain, as well as visual disturbances (blurred vision and oscillopsia). They were asked if these were head movements that induced these symptoms. A shortened version of the Vestibular Symptom Scale (VSS) was used to summarize the dizziness (vertigo and imbalance) and anxiety scoring. The VSS consists of 15 items divided into 2 sub-scales: 8 items relating to vertigo-balance (VSS-V, score ranging $0-32$ ), and 7 items relating to autonomic-anxiety symptoms (VSS-A, score ranging 0-28). The Duke Anxiety-Depression Scale (Duke-AD) was used as a screening instrument for anxiety and depression. The Duke-AD is a 7-item brief screener for both clinical anxiety and depression. The Duke-AD score cutoff point of $>5$ on a $0-14$ scale was used.

\section{VNG tests}

The VNG examination was performed using the computerized videonystagmography set by VNG-Ulmer, Synapsys SA. Real-time analysis of eye movements was performed using light-occluded VNS Goggles (an IR high resolution CCD camera). The system was connected to an Ulmer MED4 rotary chair and enabled the simultaneous recordings of chair and eye movements.

The bithermal Fitzgerald-Hallpike caloric test was performed with water stimulation $\left(30^{\circ} \mathrm{C}\right.$ and $\left.44^{\circ} \mathrm{C}\right)$. Reactivity was calculated by the system as the sum of a better ear response and compared between groups. 
To assess VOR and COR, the sinusoidal pendular test with a frequency of $0.25 \mathrm{~Hz}$ and an increasing-decreasing amplitude of $0-49^{\circ}$ was performed. The patients were tested under 3 conditions:

1) while turning around visible settings; the stimulation was both visual and vestibular, and visual-vestibular interactions were assessed (visual-vestibulo-ocular reflex, VVOR);

2) while seated in absolute darkness, motionless; the stimulation was strictly vestibular; VOR was evaluated and recorded;

3 ) while seated in the absence of any visual or vestibular input (in absolute darkness), the patient's head was held manually by the technician to be motionless and the body was rotated by the chair (trunk-to-head rotation).

To control the lack of head movement, a laser pointer was mounted on the goggles and the still light dot was controlled by a technician; COR was elicited and recorded. In every case, the gain, i.e., the eye movement to chair movement ratio, was calculated.

\section{VNG head turning test}

During the VNG head turning test (VNG-HTT), the patient was sitting upright, in absolute darkness, wearing VNG goggles. The patient's head was rotated gently about the vertical axis to the end point of rotation (close to $90^{\circ}$ ), and this position was maintained for $30 \mathrm{~s}$. During this period, the examiner encouraged the patient to keep the eyes in the center of the orbit. The eyes were monitored for the nystagmus development. The slow phase velocity (SPV) of nystagmus was recorded, and its horizontal, vertical and torsional components were analyzed in the last $10 \mathrm{~s}$ of the recordings to avoid vestibular stimulation. The torsional component was used for calculations.

\section{Statistical analysis}

The ANOVA test was used to compare the mean values of tested parameters between the 3 groups, and Levene's test was conducted before that comparison. When Levene's test revealed significance, the non-parametric Kruskal-Wallis test was performed to compare the means. Then, the results were compared one-to-one between the groups, using Student's t-test or non-parametric Mann-Whitney U test. Finally, the $\chi^{2}$ test was performed to compare the frequency of these test results between the $\mathrm{R}+$ and $\mathrm{R}$-groups.

This project was approved by the Research Ethics Committee of the Nofer Institute of Occupational Medicine (Project No. 12/2015). Clinical investigations were conducted according to the principles stipulated in the Declaration of Helsinki.

\section{RESULTS}

\section{Symptoms}

The main symptoms by study group are summarized in Table 1. The $\mathrm{R}+$ group reported more frequent non-migraine headaches, painful neck stiffness and blurred vision, as compared to the R- group.

The results of the questionnaire assessment of vestibular symptoms and psychological status are presented in Table 2. There were no statistically significant differences between the groups although the mean values of the Duke-AD questionnaire scoring were slightly higher in the $\mathrm{R}$ - group than in the $\mathrm{R}+$ group. The frequency of the positive Duke-AD scoring ( $>5$ ) was $47 \%$ in the $\mathrm{R}+$ group and $73 \%$ in the $\mathrm{R}$ - group $(\mathrm{p}=0.0044)$.

\section{VNG tests}

The COR gain and the VNG-HTT SPV were significantly higher in the $\mathrm{R}+$ group than in the $\mathrm{R}$ - group. Besides, the COR gain, the VNG-HTT nystagmus and caloric reactivity were higher among the $\mathrm{R}+$ subjects than in the healthy control group (Table 3). No correlations were observed between the COR gains and the VNG-HTT SPVs in the study and control groups. The frequency of elevated VNG-HTT (SPV $>1 \%$ ) was higher in the $\mathrm{R}+$ group $(56 \%)$ than in the $\mathrm{R}-$ group $(19 \%, \mathrm{p}=0.0321)$ and the control group $(22 \%, \mathrm{p}=0.0367)$. 
Table 1. Complaints reported by the patients during interviews of 71 subjects included in the study on vertigo and dizziness, Poland

\begin{tabular}{lccccc}
\hline \multirow{2}{*}{\multicolumn{1}{c}{ Complaint }} & \multicolumn{2}{c}{$\begin{array}{c}\mathrm{R}+ \\
(\mathrm{N}=45)\end{array}$} & \multicolumn{2}{c}{$\begin{array}{c}\mathrm{R}- \\
(\mathrm{N}=26)\end{array}$} & $\mathrm{p}$ \\
\cline { 2 - 5 } & $\mathrm{n}$ & $\%$ & $\mathrm{n}$ & $\%$ & \\
\hline Vertigo & 11 & 24 & 4 & 15 & 0.9646 \\
Dizziness & 37 & 82 & 21 & 81 & 0.8188 \\
Imbalance & 25 & 56 & 16 & 62 & 0.7188 \\
Headache & 42 & 93 & 14 & 54 & $\mathbf{0 . 0 0 0 2}$ \\
Head movement induced symptoms & 16 & 36 & 6 & 23 & 0.3180 \\
Blurred vision & 10 & 22 & 1 & 4 & $\mathbf{0 . 0 4 4 7}$ \\
Painful neck stiffness & 14 & 31 & 0 & 0 & $\mathbf{0 . 0 0 0 0}$ \\
\hline
\end{tabular}

Bolded are statistically significant differences between the $\mathrm{R}+$ and $\mathrm{R}$ - groups for $\mathrm{p}<0.05$.

The $\chi^{2}$ analysis was performed to compare the frequency of symptoms and test results between the $\mathrm{R}+$ and $\mathrm{R}$ - groups.

Table 2. Symptoms scoring according to the Vestibular Symptom Scale (VSS) and the Duke Anxiety-Depression Scale (Duke-AD) in the study on vertigo and dizziness, Poland

\begin{tabular}{lccc}
\hline \multirow{2}{*}{ Scale } & \multicolumn{3}{c}{$\begin{array}{c}\text { Symptoms scoring } \\
(\mathrm{M}(\mathrm{SEM}))\end{array}$} \\
\cline { 2 - 3 } & $\mathrm{R}+$ & $\mathrm{R}-$ & $\mathrm{p}^{\mathrm{a}}$ \\
& $(\mathrm{N}=45)$ & $(\mathrm{N}=26)$ & \\
\hline Vestibular Symptom Scale & & & 0.14455 \\
$\quad$ Vestibular & $8.1(0.4)$ & $9.7(0.7)$ & 0.10746 \\
Anxiety & $8.8(0.7)$ & $10.7(0.9)$ & 0.05842 \\
Duke Anxiety-Depresion Scale & $6.1(0.5)$ & $7.8(0.6)$ & \\
\hline
\end{tabular}

SEM - standard error of the mean.

${ }^{a} \mathrm{R}+$ vs. R-.

Table 3. The videonystagmography test results in the study on vertigo and dizziness on a group of 71 subjects, Poland

\begin{tabular}{|c|c|c|c|c|}
\hline \multirow{2}{*}{ Videonystagmography parameter } & \multicolumn{3}{|c|}{$\begin{array}{c}\text { Parameters } \\
{[\% / \mathrm{s}]} \\
(\mathrm{M}(\mathrm{SEM}))\end{array}$} & \multirow[t]{2}{*}{$\mathrm{p}^{\mathrm{a}}$} \\
\hline & $\begin{array}{l}\mathrm{R}+\text { group } \\
(\mathrm{N}=45)\end{array}$ & $\begin{array}{l}\mathrm{R}-\text { group } \\
(\mathrm{N}=26)\end{array}$ & $\begin{array}{l}\text { controls } \\
(\mathrm{N}=36)\end{array}$ & \\
\hline Caloric reactivity & $50.7(2.55)^{*}$ & $44.5(3.80)$ & $38.4(2.85)$ & 0.008 \\
\hline VOR gain in the kinetic test & $0.49(0.02)$ & $0.45(0.03)$ & $0.49(0.02)$ & 0.819 \\
\hline COR gain in the kinetic test & $0.22(0.02)^{1 *}$ & $0.09(0.02)$ & $0.10(0.02)$ & 0.000 \\
\hline VNG-HTT SPV & $1.44(0.15)^{2 *}$ & $0.83(0.21)$ & $0.81(0.15)$ & 0.001 \\
\hline
\end{tabular}

To compare the mean values of the study parameters between the groups, the ANOVA or Kruskal-Wallis test was used.

SEM - standard error of the mean.

COR - cervico-ocular reflex; SPV - slow phase velocity of the nystagmus elicited by head turning; VNG-HTT - head torsion test;

VOR - vestibulo-ocular reflex.

a $\mathrm{R}+$ vs. controls.

$\mathrm{R}+$ vs. R-: ${ }^{1}$ COR gain $\mathrm{p}=0.000360 ;{ }^{2}$ VNG-HTT SPV $\mathrm{p}=0.023544$.

* Statistically significant differences between the study group and the control group.

Bolded are statistically significant differences between the study groups for $\mathrm{p}<0.05$. 
A positive relationship was found in the $\mathrm{R}+$ group between the VOR and COR results (Figure 1a); no such correlation was observed in the R-group (Figure 1b) and the control group (Figure 1c). A positive correlation was also found between the COR and VOR directional preponderances (COR-DP and VOR-DP) in the $\mathrm{R}+$ group only (Spearman's rank correlation coefficient $0.39, \mathrm{p}=0.003$ in the $\mathrm{R}+$ group, $0.14, \mathrm{p}=0.486$ in the $\mathrm{R}$ - group, and $0.11, p=0.520$ in the control group).

\section{DISCUSSION}

Vertigo and dizziness are quite common symptoms, for which cervical etiology may be suspected in some cases. One of the pathophysiological theories assumes that vertigo may be produced in response to distortion of vestibular and neck afferent impulses. Deep intervertebral neck muscles and high cervical joint capsules and ligaments are strongly responsible for proprioceptive activation; thus, the muscle and ligament tension caused by an improper (asymmetric) neck posture at the $\mathrm{C} 1-\mathrm{C} 2$ level has been assumed to be the source of increased proprioception and, probably, dizziness. This study was based on the assumption that, in the reference study group, there were signs of proprioceptive activation caused by asymmetric increased muscle tension. The clinical picture in this group was also explored.

The study group included patients from the Audiology Clinic and the Neurology Department, who suffered from vertigo and imbalance, as well as reported frequent headaches. The FRT and muscle palpation were used to divide patients into 2 study groups. The $\mathrm{R}+$ group included patients who presented asymmetric muscle tension and a one-side diminished range of head motion as compared to the other side. The R-group included subjects without muscle tension on palpation and abnormalities in FRT. Both the $\mathrm{R}+$ and $\mathrm{R}-$ study groups presented transient vertigo, dizziness and imbalance, whose origin could not be simply explained by the performed examination. Additionally, a group of healthy volunteers were tested using
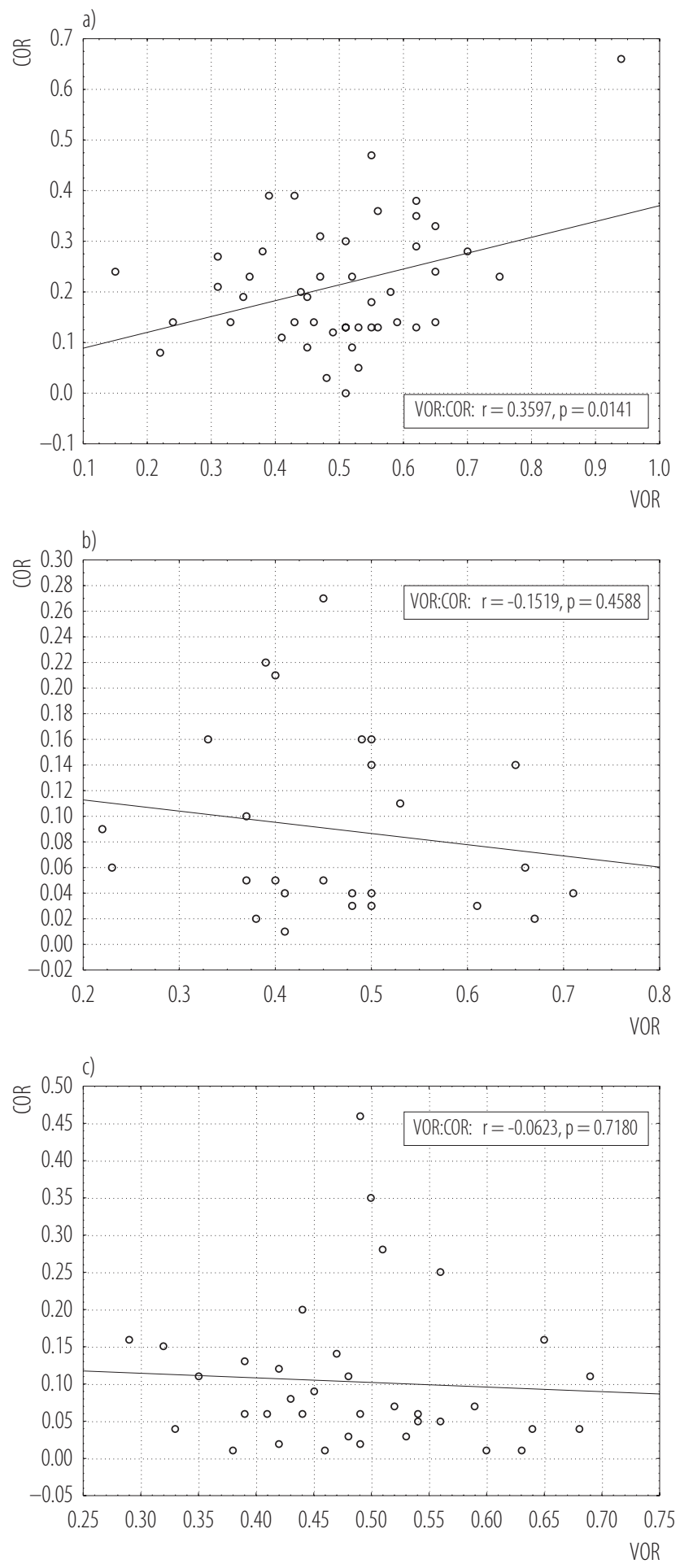

Figure 1. The correlation between the gains of vestibulo-ocular reflex (VOR) and cervico-ocular reflex (COR) in the pendular kinetic test; a) the $\mathrm{R}+$ group, b) the R-group, c) control volunteers 
this study protocol. No one in the volunteers group suffered from vertigo, dizziness, imbalance, painful neck stiffness or chronic headaches. Moreover, FRT and palpation did not reveal any abnormalities in this group; thus, the authors could not single out a non-symptomatic reference group that would be FRT positive. The mean age and age distribution were similar in the $\mathrm{R}+$ and control groups, while the R-group was significantly older.

As Brandt and Bronstein [1] have suggested, cervical dizziness may be suspected if other known reasons for vertigo, unsteadiness and oscillopsia are ruled out. In this study, the most common labyrinthine and vestibular nerve lesions were excluded by careful clinical examination, VNG caloric, kinetic tests and, if required, neuroimaging in both study groups. Migraine and psychogenic vertigo were taken into consideration in the questionnaire and neurological assessment. Patients with migraine were excluded from the study. Studies of patients with dizziness suggest that primary anxiety disorders cause dizziness in about $30 \%$ of the dizzy population, anxiety and depression may be a result of dizziness as well [21]. In this study, the anxiety level was measured with the Duke-AD. This simple questionnaire has been shown to be an effective brief screener for clinical anxiety and depression [22]. According to the Duke-AD, the anxiety level was slightly higher in the $\mathrm{R}$ - group than in the $\mathrm{R}+$ group. Concerning the possible vertigo explanation, anxiety or depression might explain dizziness in $73 \%$ of the R-group, and only in $47 \%$ of the $\mathrm{R}+$ group.

The main clinical differences between the $\mathrm{R}+$ and $\mathrm{R}-$ study groups concern the frequency of neck pain and/or stiffness, headaches other than migraine and transient episodes of blurred vision. Frequent headaches which were observed in $>90 \%$ of the $\mathrm{R}+$ group were linked to increased muscle tension and a diminished cervical range of motion. Some headaches which originate in cervical structures (including the $\mathrm{C} 1-\mathrm{C} 2$ junction) are classified as secondary cervical headaches according to ICHD-3 when the cervical background is proven.
In order to reveal specific neck pathology, this study focused on 2 clinical tests: FRT and muscle palpation. Additionally, open-mouth X-ray scans were performed in the study groups to confirm the functional findings. Flexion-rotation test is a simple clinical test used to assess dysfunction at the $\mathrm{C} 1-\mathrm{C} 2$ motion segment [23] and is characterized by high sensitivity and specificity to detect the presence or absence of cervical joint dysfunction [24]. Although patients with serious conditions such as cervical instability were excluded from the study, a subtle asymmetry at the C1-C2 level was observed in $>80 \%$ of the $\mathrm{R}+$ group, and in no subject in the $\mathrm{R}$ - group, on $\mathrm{X}$-ray scans. These findings confirmed the assumptions of asymmetric cervical abnormalities being the basis for functional asymmetry found in clinical tests. The upper cervical region is highly equipped with proprioceptors; thus, asymmetry in rotation restriction at this level could be linked to a disturbed and asymmetrical proprioceptive input.

The objective signs of cervical pathology were investigated by VNG kinetic and VNG-HTT tests. The ocular stabilization reflexes serve the purpose of stabilizing the visual image on the retina during head movements. COR is a week reflexive eye response that is elicited by rotation of the neck with the head still, in darkness. The trunk-tohead movements stimulate the proprioception of muscles and the facet joints of the cervical spine. Some studies have outlined that in healthy subjects the COR gain may be absent or not higher than 0.1 [13], depending on the frequency and velocity of body rotation and the recording technique. It is believed that COR can compensate for the loss of vestibular function, particularly in low frequencies of motion, which was observed in labyrinthine defective patients [25]. The significant negative correlation between the VOR and COR gains was found in healthy subjects whose VOR decreased with age [15]. In this study, the COR gain was higher in the $\mathrm{R}+$ group than in the $\mathrm{R}$ - and control groups, while the mean values of the kinetic VOR 
gain were similar in all groups. High vestibular response in the $\mathrm{R}+$ group was confirmed by high caloric reactivity, which was significantly higher in the $\mathrm{R}+$ group than among healthy controls. Moreover, Figure 1a presents a statistically significant positive relationship between the kinetic VOR in the sinusoidal pendular test and COR in this test for the $\mathrm{R}+$ group, which was not observed either for the R-group or for healthy controls. A similar proprioreceptive overstimulation was found in whiplash injury patients [18], as a result of reduced neck mobility and/or cerebellar disturbances. The positive correlation between COR asymmetry and VOR asymmetry, assessed by directional preponderance, was observed in the $\mathrm{R}+$ group only, which may suggests some interaction between reflexes. The asymmetric modulation of VOR may, in some people, result from a transient blurred vision, vertigo or dizziness and imbalance.

Nystagmus elicited by persisted head torsion was observed in $\mathrm{R}+$ patients in VNG-HTT. This test is also known as the vertebral artery test. The nystagmus observed after torsion of the head could be caused by changes in neck muscles, joints, vascular structures or somatosensory innervation. It has been suggested that when the vertebral artery test reveals strong nystagmus, it may originate from vascular impingement, but weak horizontal nystagmus may be caused by alterations in the cervical root tone [3]. L'Heureux-Lebeau et al. [26] have found that subjects with cervicogenic dizziness exhibit $>2 \%$ s nystagmus during the cervical torsion test, which is significantly more than in subjects with benign paroxysmal positional vertigo. Weak nystagmus observed in this study could be rather categorized as afferent in origin. The increased muscle and joint tension might produce the response in the mechanism of central mishmash between the expected and supplied impulsation. The lack of correlation between COR assessment and VNG-HTT may be caused by the testing conditions: COR was measured in dynamic conditions, when impulses elicited by the left/right side movement were compared;
HTT nystagmus was produced in static conditions, when the head was rotated to one side and kept in that position. Moreover, the literature concerning the efficacy of HTT as a test for cervical dizziness is very sparse.

\section{CONCLUSIONS}

Patients with asymmetric restriction in neck rotation and increased neck muscle tension reveal the tendency to have an increased response in the vestibular system, with coexisting asymmetric COR upregulation. Clinically, such patients might develop blurred vision spells, painful neck stiffness and headaches. Increased cervical afferent proprioception could be an explanation for these symptoms in patients with neck pathologies, but further research is needed to investigate the relationships between the activation of cervical mechanoreceptors and dizziness.

\section{REFERENCES}

1. Brandt T, Bronstein A. Cervical vertigo. J Neurol Neurosurg Psychiatry. 2001;71:8-12, https://doi.org/10.1136/jnnp.71.1.8.

2. Hulse M. Disequilibrium caused by a functional disturbance of the upper cervical spine, clinical aspects and differential diagnosis. Manuelle Medizin. 1983;1(1):18-23.

3. Hain T. Cervicogenic causes of vertigo. Curr Opin Neurol. 2015;28:69-73, https://doi.org/10.1097/WCO.0000000000 000161.

4. Gimse R, Tjell C, Bjørgen I, Saunte C. Disturbed eye movements after whiplash due to injuries to the posture control system. Clin Exp Neuropsychol. 1996;18:178-86.

5. Cevik R, Bilici A, Nas K, Demircan Z, Tekin RC. Non-invasive evaluation of vertebral artery blood flow in cervical spondylosis with and without vertigo and association with degenerative changes. Clin Rheumatol. 2015;29:541-6, https://doi. org/10.1007/s10067-010-1385-7.

6. Bayrak IK, Durmus D, Bayrak AO. Effect of cervical spondylosis on vertebral arterial flow and its association with vertigo. Clin Rheumatol. 2009;28:59-64, https://doi.org/10.1007/ s10067-008-0983-0. 
7. Collegde NR, Barr-Hamilton RM, Lewis SJ, Sellar RJ, Wilson JA. Evaluation of investigations to diagnose the cause of dizziness in elderly people: A community based controlled study. Br Med J. 1996;313:788-92, https://doi.org/10.1136/ bmj.313.7060.788.

8. Chen Y, Zhuang Z, Qi W, Yang H, Chen Z, Wang X, et al. A three-dimensional study of the atlantodental interval in a normal Chinese population using reformatted computed tomography. Surg Radiol Anat. 2011;9(33):801-8, https:// doi.org/10.1007/s00276-011-0817-7.

9. Biguer B, Donaldson IM, Hein A, Jeannerod M. Neck muscle vibration modifies the representation of visual motion and direction in man. Brain. 1988;111:1405-24, https://doi. org/10.1093/brain/111.6.1405.

10. Sato H, Ohkawa T, Uchino Y, Wilson VJ. Excitatory connections between neurons of the central cervical nucleus and vestibular neurons in the cat. Exp Brain Res. 1997;115:3816, https://doi.org/10.1007/pl00005708.

11. Gdowski GT, McCrea RA. Neck proprioceptive inputs to primate vestibular nucleus neurons. Exp Brain Res. 2000;35:511-26, https://doi.org/10.1007/s002210000542.

12. Huygen PL, Verhagen WI, Nicolasen MG. Cervico-ocular reflex enhancement in labyrinthine-defective and normal subjects. Exp Brain Res. 1991;87:457-64, https://doi. org/10.1007/bf00231863.

13. Schubert MC, Das V, Tusa RJ, Herdman SJ. Cervico-ocular reflex in normal subjects and patients with unilateral vestibular hypofunction. Otol Neurotol. 2004;1(25):65-71.

14. Sawyer RN, Thurston SE, Becker KR, Ackley CV, Seidman SH, Leigh RJ. The cervico-ocular reflex of normal human subjects in response to transient and sinusoidal trunk rotations. J Vestib Res. 1994;4(3):245-9.

15. Kelders WP, Kleinrensink GJ, Van Der Geest JN, de Zeeuw CI, Frens MA. Compensatory increase of the cervico-ocular reflex with age in healthy humans. J Physiol. 2003;553: 311-7, https://doi.org/10.1113/jphysiol.2003.049338.

16. Yakushin SB, Kolesnikova OV, Cohen B, Ogorodnikov DA, Suzuki J, Della Santina CC, et al. Complementary gain modifications of the cervico-ocular (COR) and angular vestibulo-ocular (aVOR) reflexes after canal plugging. Exp Brain Res. 2011;5(3-4):549-60, https://doi.org/10.1007/ s00221-011-2558-6.

17. Bronstein AM, Morland AB, Ruddock KH, Gresty MA. Recovery from bilateral vestibular failure: implications for visual and cervico-ocular function. Acta Otolaryngol Suppl. 1995;520:405-7, https://doi.org/10.3109/00016489509125283.

18. Montfoort I, Van Der Geest JN, Slijper HP, De Zeeuw CI, Frens MA. Adaptation of the cervico- and vestibulo-ocular reflex in whiplash injury patients. J Neurotrauma. 2008;25:687-93, https://doi.org/10.1089/neu.2007.0314.

19. Bryans R, Decina P, Descarreaux M, Duranleau M, Marcoux H, Potter B, et al. Evidence-based guidelines for the chiropractic treatment of adults with neck pain. J Manipulative Physiol Ther. 2014;37:42-63, https://doi.org/10.1016/ j.jmpt.2013.08.010.

20. Guo LY, Lee SY, Lin CF, Yang CH, Hou YY, Wu WL, et al. Three-dimensional characteristics of neck movements in subjects with mechanical neck disorder. J Back Musculoskelet Rehabil. 2012;1(25):47-53, https://doi.org/10.3233/BMR2012-0309.

21. Staab JP, Ruckenstein MJ. Which comes first? Psychogenic dizziness versus otogenic anxiety. Laryngoscope. 2003;113: 1714-8, https://doi.org/10.1097/00005537-200310000-00010.

22. Parkerson GR, Broadhead WE. Screening for anxiety and depression in primary care with the Duke Anxiety-Depression Scale. Fam Med. 1997;3(29):177-81.

23. Hall TM, Robinson KW, Akasaka K. Intertester reliability and diagnostic validity of the cervical flexion-rotation test. J Manipulative Physiol Ther. 2008;31:293-300, https://doi. org/10.1016/j.jmpt.2008.03.012.

24. Ogince MH, Hall T, Robinson K, Blackmore AM. The diagnostic validity of the cervical flexion-rotation test in $\mathrm{C} 1 / 2$-related cervicogenic headache. Man Ther. 2007;8(12):256-62, https://doi.org/10.1016/j.math.2006.06.016.

25. Carmona S, Nieto D. The specificity and sensitivity of uninhibited COR in labyrinthine-defective patients. Ann NY 
Acad Sci. 2005;1039:508-12, https://doi.org/10.1196/annals. 1325.055 .

26. L'Heureux-Lebeau B, Godbout A, Berbiche D, Saliba I. Evaluation of paraclinical tests in the diagnosis of cervicogenic dizziness. Otol Neurotol. 2014;12(35):1858-65, https://doi. org/10.1097/MAO.0000000000000506.

This work is available in Open Access model and licensed under a Creative Commons Attribution-NonCommercial 3.0 Poland License - http://creativecommons.org/ licenses/by-nc/3.0/pl/deed.en. 